\title{
The role of eHealth and mHealth in tuberculosis and tobacco control: a WHO/ERS consultation
}

\author{
Dennis Falzon ${ }^{1}$, Mario Raviglione ${ }^{1}$, Elisabeth H. Bel${ }^{2}$, Christina Gratziou², \\ Douglas Bettcher ${ }^{3}$ and Giovanni Battista Migliori ${ }^{2,4}$
}

Affiliations: ${ }^{1}$ Global TB Programme, World Health Organization, Geneva, Switzerland. ${ }^{2}$ European Respiratory Society, Lausanne, Switzerland. ${ }^{3}$ Department for Prevention of Non-communicable Diseases, World Health Organization, Geneva, Switzerland. ${ }^{4} \mathrm{WHO}$ Collaborating Centre for TB and Lung Diseases, Fondazione S. Maugeri, Tradate, Italy.

Correspondence: Dennis Falzon, Global TB Programme, World Health Organization, 20 avenue Appia, CH-1211 Geneva 27, Switzerland. E-mail: falzond@who.int

@ERSpublications

eHealth and mHealth in tuberculosis and tobacco control: WHO/ERS consultation http://ow.ly/Owy38

Both tuberculosis (TB) and tobacco consumption are major global public health concerns. About 9 million new cases of TB emerge each year and 1.5 million people die from the disease, despite the fact that TB is eminently curable in the large majority of cases with an affordable course of drugs [1]. Tobacco is the largest preventable cause of death in the world: almost 6 million people die from tobacco use and exposure each year, accounting globally for $6 \%$ of all female and $12 \%$ of all male deaths [2]. This number is set to increase to 8 million in 2030 , or $10 \%$ of all deaths projected to occur that year. The burden of tobacco use is greatest in low- and middle-income countries and, unchecked, this trend is likely to increase in coming decades. There is a strong association between smoking and TB [3, 4]. Smoking substantially increases the risk of contracting TB and dying from it. Recent studies of risk factors have attributed more than $20 \%$ of global TB incidence to smoking [5]. As a result, smoking cessation is one of the interventions that can prevent TB and, among those who already developed the disease, improve its outcomes [6].

While the evidence for the association between $\mathrm{TB}$ and tobacco provides the scientific basis for joint intervention, the global explosion in information and communication technology (ICT) presents new opportunities for more effective action on both fronts. The pace with which the coverage of internet and mobile telephone networks continues to grow, and with which the performance of electronic devices keeps advancing and diversifying, can only be described as revolutionary. They create new perspectives to reach larger numbers of patients and health care workers even in resource-limited settings in the world. In fact, eHealth and mHealth open up approaches for action which would have been unimaginable a mere decade ago and a groundswell of interest has been observed in recent years to employ novel means to support TB patients [7,8]. eHealth (electronic health) is the cost-effective and secure use of ICTs for health and health-related fields while mHealth, a component of eHealth, involves the provision of health services and information via mobile technologies such as mobile phones and personal digital assistants. eHealth and mHealth are referred to collectively as "digital health". Likewise, a joint initiative between the World Health Organization (WHO) and the International Telecommunications Union, "Be He@lthy Be Mobile" (mHealth4NCD.itu.int) is seeing countries as far apart as Costa Rica, India, Norway, the Philippines, Senegal, Tunisia, the UK and Zambia embrace mHealth solutions to combat tobacco, diabetes, cervical cancer, hypertension and other non-communicable diseases. What makes this initiative unique is that these state-owned programmes use mobile phones to deliver health care at national scale rather than as pilot studies. Through its work it also supports the creation of sustainable partnerships both within national programmes and at the global level.

Received: March 172015 | Accepted: March 252015

Conflict of interest: Disclosures can be found alongside the online version of this article at erj.ersjournals.com

Copyright @ERS 2015 
While some digital health interventions have been appealing and show promise, evidence for their effectiveness is still incomplete, and measures to ensure their successful implementation are not well described. Many initiatives have met with different degrees of success; as a result of insufficient evidence, support or synergic action, few of them have been scaled up sufficiently and durably to make an appreciable impact. The full potential for ICT to contribute to the control of TB and tobacco use is thus yet to be unleashed. For instance, more TB patients and healthcare workers alike can be encouraged to use mobile devices to notify TB to centralised databases, as well as to register care encounters or adverse drug reactions. Patients can be supported remotely to take daily medication over several months using video or chat functions. Cash transfers to reward patient adherence to treatment could be facilitated by mobile banking (mBanking). Caregivers could receive alerts on test results via short message service (SMS) or email sent directly from computerised laboratory information systems. And more mobile applications and web resources can be developed to inform patients and update healthcare workers. The evidence for mHealth effectiveness in non-communicable diseases is growing $[9,10]$. In tobacco control, whilst there is evidence that interventions using telephone hotlines, the internet and mobile telephones can help people to quit smoking and are useful in household surveys, there is more potential to study their role in other situations, such as to enforce smoke-free laws, to track and trace counterfeit cigarettes, to increase public awareness, to train health workers and to inform farmers about alternative crops to grow instead of tobacco.

In order to explore the opportunities to address the challenges systematically, WHO's Global TB Programme has developed a conceptual framework to profile the potential roles of digital health in TB prevention, care and control efforts, aligned to its new End TB strategy [11] (table 1). This framework groups the key digital health approaches under four functions, namely: 1) patient care; 2) surveillance and monitoring; 3) programmatic management; and 4) electronic learning (eLearning). It seeks to enhance impact by broadening the scope of action to risks for TB outside of the traditional preserve of the national TB programme, particularly tobacco use. The Global TB Programme will undertake several actions, including the review of evidence on the impact of digital health in TB control, guiding countries to channel resources towards practices proven to be effective and interventions which are likely to maximise

TABLE 1 Framework of digital health interventions for tuberculosis (TB) care and control: opportunities for integration with non-communicable diseases

Functions Sample interventions

Patient care and eDOT Virtual (video) directly observed treatment (VOT)

Drug administration monitoring devices

Enablers/incentives for adherence (cash transfers, free airtime) and quitting eHealth portal to improve continuity of care in TB and tobacco control

Mobile smoking cessation services

Measures to ensure smoke-free clinics (citizen reporting, SMS reminders)

Surveillance and monitoring

Notification of TB episodes to existing electronic surveillance systems

Reporting of adverse drug reactions (pharmacovigilance)

Household surveys on smoking using mobile phones

Studies of social determinants and smoking status

Client satisfaction polls

Operational research on transactions between community health workers, patients and facilities

Programmatic management

Stock levels of drugs, medical devices and reagents

Management and coordination of logistics

Drug ordering and management systems

Laboratory information systems

Texting of laboratory results on TB and comorbidities (e.g. HIV, diabetes)

Database of patient location, contacts and health care facilities

Access to medical files via mobile devices

eLearning

Self-teaching utilities

Online courses and information on healthy lifestyles (e.g. smoking cessation, diabetes controll

Online advice to clinicians on clinical management (e.g. www.tbconsilium.org)

Applications proposing content, such as guidelines and diagnostic aids

Social networking and mobile awareness to increase knowledge amongst patients, family members and health services staff about TB and the dangers of tobacco use

eDOT: electronic directly observed treatment. Adapted from [12] with permission from the publisher. 
benefit, supporting the scaling up and modernisation of information systems, and development of policy. Similarly, the Department for Prevention of Non-communicable Diseases of WHO is supporting initiatives such as "Be He@lthy Be Mobile" to promote large-scale adoption by countries of digital health interventions for tobacco control and management of multiple non-communicable conditions. To achieve its aims, WHO will promote more dialogue between health professionals, technical and funding partners, ICT experts and system developers.

The European Respiratory Society (ERS) has already had a fruitful collaboration with the WHO's Regional Office for Europe in promoting ICT in recent years by, among others, creating the TB Consilium, an electronic platform for clinicians to discuss the care of multidrug-resistant TB (MDR-TB) patients [13, 14]. ERS is now working with the Global TB Programme and the Department for the Prevention of Non-communicable Diseases to promote ICT further for lung health. For this reason a technical consultation on the theme of "The role of e/mHealth in TB and tobacco control" was held in Geneva on February 25-26, 2015 (figures 1 and 2) (www.who.int/tb/features_archive/ehealth_tb_consultation/en/). This meeting brought together close to 100 participants based in 23 countries, representing a broad cross-section of global expertise in TB, tobacco control and eHealth, as well as academics, funding partners, the corporate sector and end-users who are involved in the area. The discussions enabled system developers to interact closely with health professionals facing daily challenges to treat patients and manage public health interventions, and for which creative ICT solutions could provide an answer. The meeting was also an opportunity to discuss the available evidence for the impact of digital health in the care and control of tuberculosis and tobacco-related conditions. Other presentations were made on interventions which have been implemented at national scale, concepts on eLearning and about frameworks for scalability and monitoring.

While the meeting did not produce WHO policy guidelines, it is expected that it will catalyse activities which will enrich the pool of evidence and of best practices on which recommendations will eventually be based. One of the important outcomes of this meeting resulted from the discussions in four thematic

FIGURE 1 Mobile electronic devices can enhance preventive and curative work. Reproduced from the World Health Organization Photo Library with permission from the copyright holder.

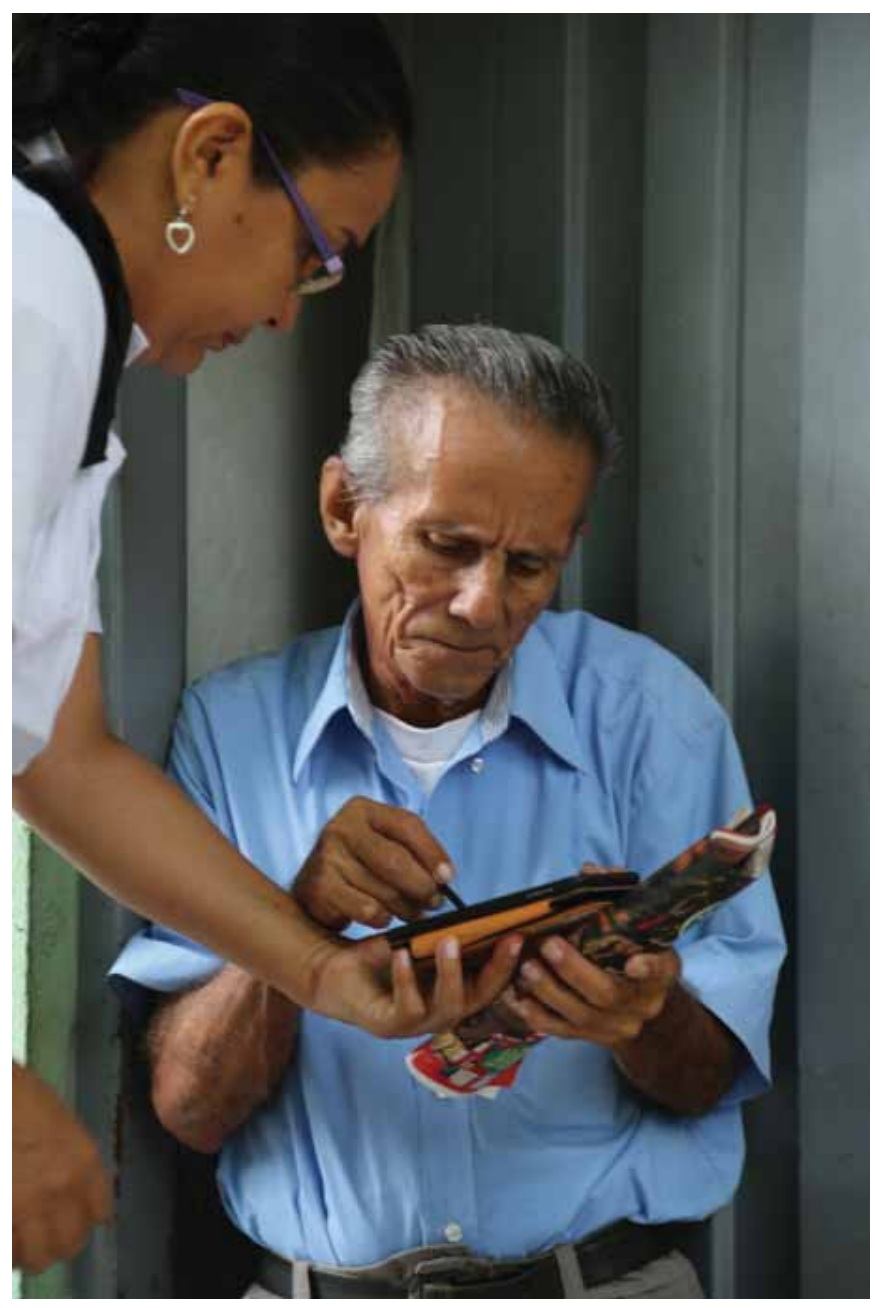



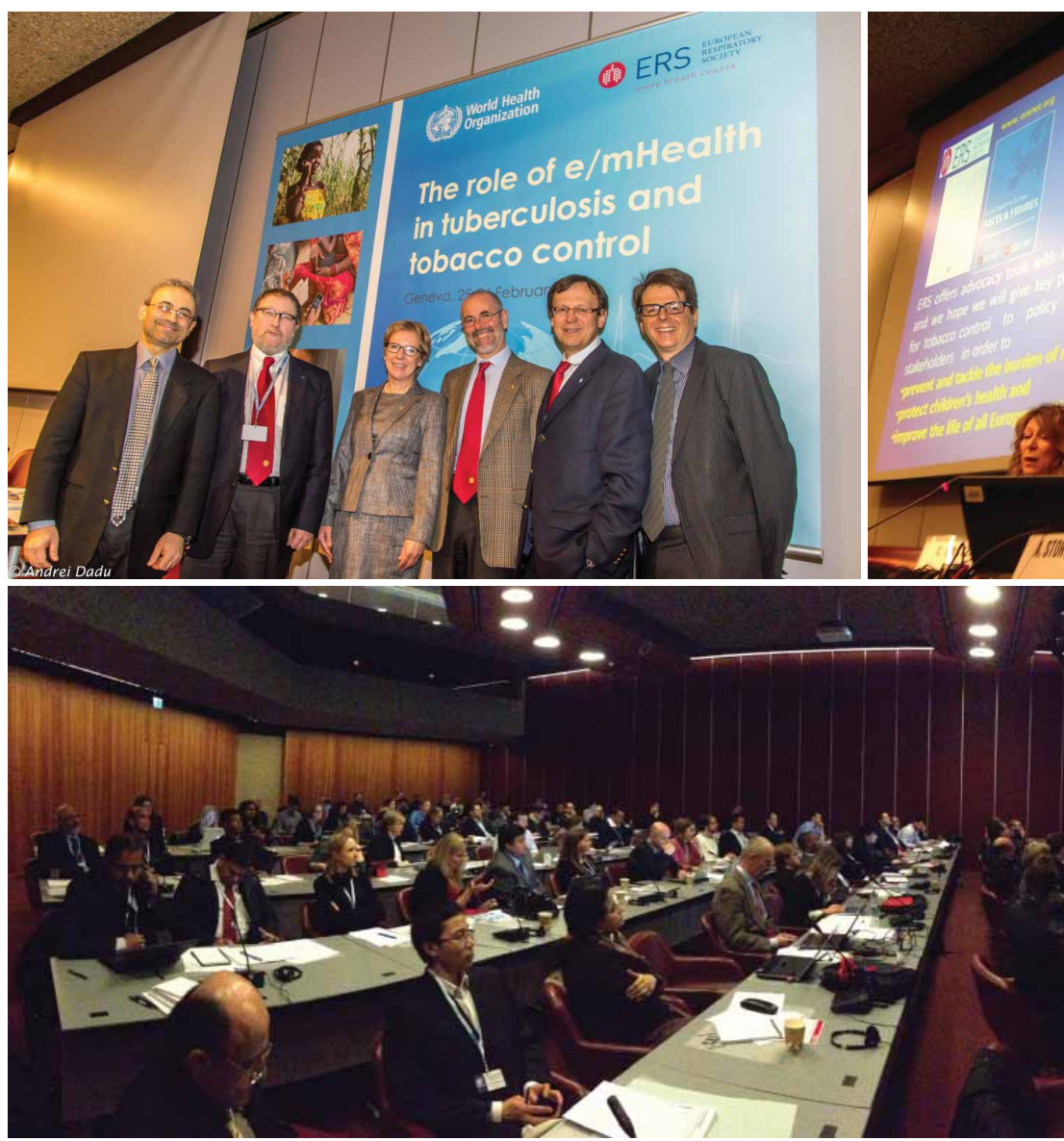

FIGURE 2 Photo collage of the World Health Organization/European Respiratory Society consultation on the role of electronic health and mobile health in tuberculosis and tobacco control held in Geneva, Switzerland on February 25-26, 2015.

working groups organised around the key functions of the conceptual framework (table 1). The members in each of these groups worked to define the characteristics of priority products - target product profiles (TPPs) - within each track. The discussions focussed on priority products that were shortlisted following an online opinion poll held ahead of the meeting: these pathfinder products were also considered to be advantageously positioned to bear impact at national or even international scale in the short term. When these TPPs are finalised they will serve to guide system developers focus on the essential features that end-users expect the digital health products to have. In parallel, a set of interventions is being planned in a number of countries, targeting the scale-up of projects that have already been started and shown benefit. A Global Task Force is being set up by the WHO Global TB Programme to steward the dual processes of TPP development for use in anti-TB activities and country projects. A strategic document which will map out the way forward will be launched at the ERS International Congress in Amsterdam in September 2015.

\section{Acknowledgements}

D. Bettcher, D. Falzon and M. Raviglione are staff members of the World Health Organization (WHO). The authors alone are responsible for the views expressed in this publication and they do not necessarily represent the decisions or policies of WHO. The authors acknowledge the contribution of numerous individuals who helped in the preparation of the consultation (www.who.int/tb/areas-of-work/digital-health/en/).

\section{References}

1 Global tuberculosis report 2014 (WHO/HTM/TB/2014.08). Geneva, World Health Organization, 2014. Available from http://apps.who.int/iris/bitstream/10665/137094/1/9789241564809 eng.pdf Date last accessed: June 10, 2015.

2 Global status report on noncommunicable diseases 2010. Geneva, World Health Organization, 2011. Available from http://whqlibdoc.who.int/publications/2011/9789240686458_eng.pdf Date last accessed: June 10, 2015.

3 A WHO/The UNION monograph on TB and tobacco control: joining efforts to control two related global epidemics (WHO/HTM/TB/2007.390). Geneva, World Health Organization, 2007. Available from www.who.int/ tobacco/resources/publications/tb_tobac_monograph.pdf Date last accessed: June 10, 2015.

4 Jiménez-Ruiz CA, Andreas S, Lewis KE, et al. Statement on smoking cessation in COPD and other pulmonary diseases and in smokers with comorbidities who find it difficult to quit. Eur Respir J 2015; 46: 61-79. 
5 Lönnroth K, Castro KG, Chakaya JM, et al. Tuberculosis control and elimination 2010-50: cure, care, and social development. Lancet 2010; 375: 1814-1829.

6 Zellweger J-P, Cattamanchi A, Sotgiu G. Tobacco and tuberculosis: could we improve tuberculosis outcomes by helping patients to stop smoking? Eur Respir J 2015; 45: 583-585.

7 Mirsaeidi M, Farshidpour M, Banks-Tripp D, et al. Video directly observed therapy for treatment of tuberculosis is patient-oriented and cost-effective. Eur Respir J 2015 [in press DOI: 10.1183/09031936.00011015].

8 Denkinger CM, Grenier J, Stratis AK, et al. Mobile health to improve tuberculosis care and control: a call worth making. Int J Tuberc Lung Dis 2013; 17: 719-727.

9 Free C, Knight R, Robertson S, et al. Smoking cessation support delivered via mobile phone text messaging (txt2stop): a single-blind, randomised trial. Lancet 2011; 378: 49-55.

10 Free C, Phillips G, Watson L, et al. The Effectiveness of Mobile-Health Technologies to Improve Health Care Service Delivery Processes: A Systematic Review and Meta-Analysis. PLoS Med 2013; 10: e1001363.

11 Uplekar M, Weil D, Lönnroth K, et al. WHO's new End TB Strategy. Lancet 2015; 385: 1799-1801.

12 eHealth in the TB response. Geneva, World Health Organization, 2014. Available from www.who.int/tb/ publications/ehealth_TB.pdf Date last accessed: June 10, 2015.

13 Blasi F, Dara M, van der Werf MJ, et al. Supporting TB clinicians managing difficult cases: the ERS/WHO Consilium. Eur Respir J 2013; 41: 491-494.

14 D'Ambrosio L, Tadolini M, Dupasquier S, et al. ERS/WHO tuberculosis consilium: reporting of the initial 10 cases. Eur Respir J 2014; 43: 286-289. 